IZA DP No. 6650

Estimating the Latent Effect of Unemployment Benefits on Unemployment Duration

Simon M.S. Lo

Gesine Stephan

Ralf Wilke

June 2012 


\title{
Estimating the Latent Effect of Unemployment Benefits on Unemployment Duration
}

\author{
Simon M.S. Lo \\ Lingnan University, Hong Kong \\ Gesine Stephan \\ $I A B$, University of Erlangen-Nuremberg \\ and IZA \\ Ralf Wilke \\ University of York \\ Discussion Paper No. 6650 \\ June 2012 \\ IZA \\ P.O. Box 7240 \\ 53072 Bonn \\ Germany \\ Phone: +49-228-3894-0 \\ Fax: +49-228-3894-180 \\ E-mail: iza@iza.org
}

Any opinions expressed here are those of the author(s) and not those of IZA. Research published in this series may include views on policy, but the institute itself takes no institutional policy positions.

The Institute for the Study of Labor (IZA) in Bonn is a local and virtual international research center and a place of communication between science, politics and business. IZA is an independent nonprofit organization supported by Deutsche Post Foundation. The center is associated with the University of Bonn and offers a stimulating research environment through its international network, workshops and conferences, data service, project support, research visits and doctoral program. IZA engages in (i) original and internationally competitive research in all fields of labor economics, (ii) development of policy concepts, and (iii) dissemination of research results and concepts to the interested public.

IZA Discussion Papers often represent preliminary work and are circulated to encourage discussion. Citation of such a paper should account for its provisional character. A revised version may be available directly from the author. 


\section{ABSTRACT \\ Estimating the Latent Effect of Unemployment Benefits on Unemployment Duration ${ }^{*}$}

We estimate the effect of a shortening of unemployment benefit entitlements on unemployment duration. Previous studies on the same or related problems have not taken into account that the competing risks duration model is not identified and we shed first light on the question whether the non identification problem may preclude informative results. It turns out that the identification bounds for the parameters of interest are very wide in the absence of strong assumptions. We suggest an assumption on the dependence structure between risks which is milder than what conventional duration models assume. Under this assumption, the identification bounds are tighter and become informative for the direction of the treatment effect. We find evidence that the unemployed with higher pre-unemployment earnings are more likely to enter full-time employment and, in particular, subsidized selfemployment.

JEL Classification: $\quad \mathrm{C} 34, \mathrm{C} 41, \mathrm{~J} 64$

Keywords: dependent censoring, partial identification, difference-in-differences, unemployment duration, unemployment benefits

Corresponding author:

Gesine Stephan

Institute for Employment Research (IAB)

Regensburger Str. 104

D-90478 Nuremberg

Germany

E-mail: gesine.stephan@iab.de 


\section{Introduction}

The effect of unemployment benefits on unemployment duration has been investigated in numerous theoretical and econometric studies because it is an important topic for the society and often discussed by the public. Also, the identifiability of the effect is hampered by several important methodological problems which still need to be resolved. Various contributions have developed comprehensive economic theory (e.g. Mortensen, 1977, and van den Berg, 1990) and flexible econometric models have been applied to comprehensive data to obtain insightful empirical results (e.g. van Ours and Vodopivec, 2006, and Schmieder, von Wachter and Bender, 2012). All models, however, still impose a number of assumptions, which are hard to verify.

In this paper, we contribute to this literature by relaxing some of the assumptions on the duration model. Our empirical strategy is unconventional as it considers an non-identified unemployment duration model and estimates bounds for quantities of interest. In particular, we estimate a competing risks unemployment duration model in which the unemployed can make a transition to various destination states. We do not analyse overall unemployment duration (e.g. the distribution of the minimum of the competing risks) because we want to distinguish between desired destinations (such as job taking) and less desired destinations (such as training and the secondary labor market). If the total effect on unemployment duration is mainly driven by changes in transition times into the secondary labor market, this would lead to rather different policy conclusions than if it was due to changes in job taking times. Analysing different latent distributions allows us to obtain much more detailed insights how the unemployment compensation system affects individual labor market outcomes.

Without assuming the dependence structure between risks or the functional form of the marginal distributions of latent durations, the competing risks model is not identified. Instead of imposing assumptions on the dependence structure, we construct bounds for the estimated treatment effect on unemployment duration to reflect the problem of partial identification. Conceptually different from confidence intervals due to random sampling error, these bounds do not disappear if the number of observations goes to infinity. As an extension to previous nonparametric approaches, we use a regression model with many covariates to control for observable variables. This enables us to estimate treatment effects on conditional distributions. In contrast to related empirical studies we do not directly estimate the marginal distributions of latent durations. In- 
stead, in a first step we estimate cumulative incidence curves for all risks using a semi-parametric hazard model for the sub-distribution function (Fine and Gray, 1999). In a second step we apply a regression version of the Copula Graphic estimator (Zheng and Klein, 1995) to determine the conditional latent marginal distributions (Lo and Wilke, 2011). This model has the attractive feature that it directly estimates an identified quantity without imposing direct functional form assumptions on the latent distributions - something that would be hard to verify given the nonidentifiability of the model (see Honoré and Lleras-Muney (2006) for a non-identified model with direct assumptions on the marginals).

While estimation of cumulative incidences is often common practise in biometrical research, it is less common in applied econometrics. The main criticism about working with cumulative incidences is that they are observed empirical patterns, but lag a clear causal interpretation as they are jointly determined by the dependence structure between risks and the marginal distributions. It is therefore hard to interpret cumulative incidences, although the actual empirical figures are often of high interest in themselves. Our approach addresses this weakness by determining how marginal distributions change due to variation in cumulative incidences. We are therefore able to assess if the policy reform under investigation affected the data generating process and not just observable empirical figures.

Our empirical approach benefits from access to a rich data source. We use a large and recent sample of administrative individual data to evaluate an important policy change in Germany. In 2006, the unemployment benefit entitlement lengths were reduced for older unemployed while they remained constant for the younger. We exploit this nicely designed policy change for estimating its effect on the distribution of failure times to various destination states. In particular, we consider recalls to the pre-unemployment employer, transitions to low-wage full-time employment, other full-time employment, and subsidized self-employment. Empirical research on previous reforms of the German unemployment benefits uses inferior data. Hunt (1995) uses comparatively small German household survey panel data. As in this paper, Lee and Wilke (2009), Arntz et al.(2008) and Lo and Wilke (2010) use large administrative individual data but their data do not comprise information on training measures, subsidized self-employment and job search which are used in this paper. For this reason, we are able to take into account additional important risks. Moreover, we apply a semi-parametric regression framework for the sub-distributions to control for covariates - in contrast to the previous nonparametric analysis - and we therefore estimate conditional treatment 
effects. Without imposing restrictive assumptions on the dependence structure, the resulting bounds for the reform effect are very wide. Under an independence assumption, the bounds are tight enough to make a number of interesting observations. We obtain empirical evidence for the existence of sizable treatment effects for a number of risks. We also observe a different timing of the effects - some arise at expiration of benefits, while others occur after expiration.

The structure of the paper is as follows. Section 2 describes the institutional framework in Germany and the data. Section 3 sketches the econometric approach, followed by the presentation of the empirical results in Section 4. The final section draws several policy implications which are derived from the novel insights of the empirical analysis.

\section{Institutional Background and Data}

The German unemployment compensation system consists of contribution based unemployment benefits and tax funded basic income support for needy unemployed. Unemployment benefits are financed mainly through unemployment insurance contributions of workers and firms (experience rating does not apply). The replacement rate amounts to 60-67 percent of the previous wage (dependent on whether there are dependent children in the household or not), while the duration varies with the employment history of workers. After the exhaustion of unemployment benefit entitlements, needy unemployed jobseekers are entitled to basic income support the level of which does not depend on former earnings (since 2005). A fundamental shortening of maximum unemployment benefit entitlement lengths - announced already during 2003 - took place in February 2006 (see Table 1). While the reform affected all workers of age 45 and older, the reduction was larger for older age groups. Since basic income support does not depend on pre-unemployment earnings, the decrease in unemployment compensation at expiration of unemployment benefits is greater for high pre-unemployment earners. There is actually no decrease for low earners, if they are entitled for means tested basic income support. This is why we split our sample into low and non-low pre-unemployment earners, as we expect larger effects for the latter group. We define low-wage workers to be those whose last wage rate amounted to less than two third of the median wage. This is the definition of low-wages used by official statistics (BA Statistik 2010) and therefore the underlying definition for public debate.

The 2006 reform was a well defined natural experiment. Dlugosz et al. (2009) analyse changes 
Table 1: The 2006 reform of unemployment benefit entitlement lengths in Germany.

Maximum entitlement length in months

\begin{tabular}{cccc} 
Age & Until $1 / 2006$ & $2 / 2006$ to $12 / 2007$ & Reduction \\
\hline$<45$ & 12 & 12 & 0 \\
$45-46$ & 18 & 12 & 6 \\
$47-51$ & 22 & 12 & 10 \\
$52-54$ & 26 & 12 & 14 \\
$55-56$ & 26 & 18 & 8 \\
$>56$ & 32 & 18 & 14 \\
\hline \hline
\end{tabular}

in unemployment inflows in response to the same reform and find evidence for a decrease for workers age 52 and older. They also observe anticipation effects of the reform in the three months ahead of the policy change $(11 / 2005$ to $1 / 2006)$ for all affected age groups. Although these effects were rather small for persons in the age range 45-51, they were quite large for workers aged 52 and older with an increase in the transition rate into unemployment by at least (dependent on the age group) one half. The results of Dlugosz et al. (2009) therefore suggest that the composition of unemployed has changed in response to the reform in particular for the aged 52 and older. We focus in our analysis on the aged 45-46 because this group had the smallest anticipation effect and there was no systematic decrease in unemployment inflows after the reform. In order to eliminate anticipation effects, we exclude inflows from the period 10/2005 to 2/2006 from our analysis. We have checked the sensitivity of our results by increasing this window by several months and did not find any evidence for changes in the results.

Our analysis uses a 25-percent-sample of the Integrated Employment Biographies of the Institute for Employment Research (IAB). These individual data are drawn from several linked administrative sources and contain daily spell information about employment periods subject to social security contributions, job seeking periods, participation in active labor market programs, and unemployment benefit and unemployment assistance claim periods. While employment periods and unemployment compensation claim spells are available since 1991 for the whole of Germany, the other registers are not fully available before the year 2000. Our version of the data is right censored; the data set ends at the end of 2008 .

Our sample of unemployment durations consists of unemployment inflows between January 2004 and December 2007, except the period 10/2005 to 2/2006 for the reasons mentioned above. The period 2004-2005 is the pre-reform period, while the period 2006-2007 is the post-reform (inflow) period. For the reasons already provided, our analysis restricts itself to a comparison 
of the age groups 40-44 (control group) and 45-46 (treatment group). We restrict our sample to unemployed who would have had the maximum entitlement length for unemployment benefits under pre-reform regulations. This ensures the comparability of the pre-reform and post-reform sample. We focus on the group of male unemployed with full-time employment before unemployment (part-time employment is rather uncommon among males). Because special regulations apply to seasonal unemployment in the construction sector, we exclude workers whose last job was located in this sector.

The data consist of employment periods subject to social security contributions and contact periods with the German Federal Employment Agency. They do not contain information if an individual is unemployed but not registering at the employment agency, has (temporarily) withdrawn from the labor market, has life-time tenure as a civil servant, or self-employed without being subsidized. This implies that unemployment duration can be defined in various ways in these data, depending on how unobserved oeriods are treated. For the following analysis, we define an unemployment spell as a sequence of spells of registered unemployment, unemployment benefit receipt, or participation in an active labor market program (with the exception of subsidized employment or self-employment or a long training program of at least 3 months), without any gap of more than a month. This is a lower bound of the true unemployment duration. We have also computed an upper bound for the true unemployment duration, which also covers the unobserved periods (see also Arntz et al., 2008). A sensitivity analysis has shown that the point estimates were similar for the two definitions, thus we do not present the results. We censor all unemployment spells at 720 days, as this is well beyond the treatment period between 365 and 550 days. If an observation is censored in our data, it is independently censored. Our sample contains overall around 60,000 observations (see Table 2) among them around 15,000 with low pre-unemployment earnings. The number of multiple spells is low (around 1,000) in our sample.

Because the level of unemployment benefits might affect, for example, the duration of taking up a low paid job or a high paid job differently, we perform a competing risks analysis. We distinguish between desired and less desired exit states. This is important as the consequences of an unemployment reform cannot be solely assessed on the grounds of a reduction in overall unemployment duration. In particular, we consider five states: recall to the previous employer, low-wage full-time employment, other full-time employment (non low-wage), subsidized self-employment, and other or unknown states. Other states includes entry into part-time employment, into the 
secondary labor market, and into long training programs. Unknown states are exits from unemployment, where the data provide no information on the eventual fate. The last risk is thus a pooled risk and therefore it does not have a direct interpretation. We assume that non-low wage full-time employment is the generally desired exit state, because the unemployment period is terminated by a transition into a job, while subsidized self-employment and other or unknown states are less desired as in most cases the individual still claims some form of benefit or subsidy or is economically inactive. Transitions into low-wage employment are considered to be less desired if an individual had a higher wage before unemployment, as it would constitute a decrease in the job quality associated with a decrease in wage. In our application, we do not assume independence between the risks.

Note that in 8/2006 eligibility criteria for self-employment subsidies for unemployment benefit claimants were altered. Before the change, any unemployment benefit claimant was eligible for these subsidies, while after the change it required a remaining entitlement period of 90 days. As will be seen later, this policy change is clearly visible in cumulative incidence curves (entries into self-employment occur earlier during an unemployment spell after this modification took place). As this modification affected treatment and control group in the same way, it does not hamper our approach to identify the effects of unemployment benefits.

Table 2 describes the distribution of destination states in our sample. 15 to 20 percent of males with low pre-unemployment wages return to the previous employer. Around a third enter a lowwage full time job and around 10 percent a non low-wage full time job at another employer. Less than 10 percent take up subsidized self-employment, and around 20 percent exit into the pooled remainder state. For unemployed with non low pre-unemployment wages, there are around 10 percent recalls and entries into low-wage jobs at another employer, while around 40 percent enter a new non low-wage job. Around 15 percent take up subsidized self-employment and around 20 percent exit into an unknown or other state. Of those exiting into an unknown or other state, entry into an unknown state turned out to be most important option.

In our econometric analysis we employ a regression model to control for a number of observable variables which affect the duration of unemployment. These include socio-demographic characteristics (married, education, nationality), labor market history (since the 1990s), characteristics of last job (wage, status, sector affiliation, firm size). and regional characteristics (federal state). In order to eliminate inconsistencies in the education and the nationality variable, we impute these 
Table 2: Distribution of observed transitions, sample size, and median unemployment duration (in days) by group and destination state

\begin{tabular}{lcccccccc}
\hline Group & \multicolumn{3}{c}{ Low-wage males } & \multicolumn{3}{c}{ Non low-wage males } \\
Age & \multicolumn{2}{c}{$40-44$} & \multicolumn{2}{c}{$45-46$} & \multicolumn{2}{c}{$40-44$} & \multicolumn{2}{c}{$45-46$} \\
Time period & Pre & Post & Pre & Post & Pre & Post & Pre & Post \\
\hline Column proportion & & & & & & & & \\
Recall & 0.18 & 0.15 & 0.20 & 0.15 & 0.10 & 0.07 & 0.09 & 0.06 \\
Low-wage full time & 0.32 & 0.34 & 0.33 & 0.35 & 0.13 & 0.11 & 0.12 & 0.12 \\
Other full time & 0.11 & 0.14 & 0.10 & 0.12 & 0.38 & 0.42 & 0.38 & 0.40 \\
Subsidized self-employment & 0.08 & 0.08 & 0.07 & 0.08 & 0.15 & 0.16 & 0.15 & 0.15 \\
Unknown and other & 0.19 & 0.20 & 0.17 & 0.21 & 0.16 & 0.19 & 0.17 & 0.22 \\
$\quad$ - Part-time & 0.02 & 0.03 & 0.02 & 0.04 & 0.02 & 0.01 & 0.02 & 0.01 \\
$\quad$ Long training & 0.02 & 0.04 & 0.02 & 0.04 & 0.03 & 0.05 & 0.04 & 0.05 \\
$\quad$ - Secondary labor market & 0.04 & 0.02 & 0.03 & 0.02 & 0.01 & 0.004 & 0.01 & 0.01 \\
$\quad$ - Unknown & 0.11 & 0.11 & 0.10 & 0.11 & 0.11 & 0.13 & 0.11 & 0.15 \\
Censored & 0.12 & 0.10 & 0.12 & 0.10 & 0.07 & 0.04 & 0.09 & 0.05 \\
N of observations & 7,134 & 5,126 & 1,817 & 1,346 & 19,148 & 15,051 & 5,740 & 4,526 \\
$\quad$ Median duration & 191 & $146^{*}$ & 198 & $153^{*}$ & 174 & $122^{*}$ & 207 & $138^{*}$ \\
\hline \hline
\end{tabular}

*Unemployment spells beginning in 2006 or earlier

variables along the lines suggested by Fitzenberger et al. (2006) and Wichert and Wilke (2012). Table 3 in the Appendix presents descriptive statistics of the regressors, for the entire groups of low-wage males and non low-wage males as well as separately by age group and treatment status. Comparing the groups of previous low-wage and non low-wage earners, those with a low-wage job had been working more frequently as unskilled blue-collar workers, in the temporary agency sector, in smaller firms and in East German federal states. Previous non low-wage earners more often have a university degree, had worked as white collar workers, and had been employed in manufacturing. The wage rate in the previous job has been more than twice as high among previous non low-wage workers. Table 4 in the Appendix describes the sample by destination state.

\section{$3 \quad$ Econometric Model}

We consider a competing risks unemployment duration model with five risks $(j=1, \ldots, 5)$ which were outlined in the previous section. $T_{j}$ is the latent duration until a transition to risk $j$ would take place. It is a random variable which is drawn from a marginal distribution function $F_{j}(t ; \mathbf{x})=$ $P\left(T_{j} \leq t ; \mathbf{x}\right)$ with $\mathbf{x}$ is a row vector of observable covariates. The marginal survival function is $S_{j}(t ; \mathbf{x})=1-F_{j}(t ; \mathbf{x})$. Due to the competing risks structure, it is only possible to observe $(T, \delta, \mathbf{x})$, 
where $\delta=\operatorname{argmin}_{j}\left\{T_{j}\right\}$ is the observed destination state and $T=\min _{j}\left\{T_{j}\right\}$ is the observed length of the unemployment period. Let $Q_{j}(t ; \mathbf{x})=P\left(T_{j} \leq t, \delta=j ; \mathbf{x}\right)$ be the cumulative incidence curve for risk $j$. This is the distribution of observed transitions to risk $j$; it is also called a subdistribution as it does not attain the value 1 as $t$ goes to infinity. An attractive feature of $Q_{j}$ is that it is identifiable and that various parametric and semi-parametric estimators have been developed (e.g. Jeong and Fine, 2007, Peng and Fine, 2009). In this paper, we apply the semi-parametric proportional hazard model for $Q_{j}$ which was suggested by Fine and Gray (1999). In this model, it is assumed that

$$
\phi_{j}(t ; \mathbf{x})=\phi_{j 0}(t) \exp (\mathbf{x} \beta)
$$

where $\phi_{j}($.$) is the hazard of the subdistribution and is defined as$

$$
\begin{aligned}
\phi_{j}(t ; \mathbf{x}) & =\lim _{\Delta t \rightarrow 0} \frac{1}{\Delta t} P(t \leq T \leq t+\Delta t, \delta=j ; T \geq t \cup(T \leq t \cap \delta \neq j), \mathbf{x}) \\
& =-d \log \left\{1-Q_{j}(t ; \mathbf{x})\right\} / d t,
\end{aligned}
$$

$\phi_{j 0}(t)$ is unknown but nonnegative. $\beta$ is a column vector of unknown coefficients. While $Q_{j}$ and $\phi_{j}$ are identifiable, they do not have a causal interpretation as $Q_{j}$ is determined by $F_{j}$ and the dependence structure between risks. Still subdistribution models are often considered in biometrics as the observed distributions are also of interest itself. While being an informative descriptive tool, they are less frequently considered in the economic impact evaluation literature. While we will be also considering changes in $Q_{j}$ in response to the policy reform, our main focus will be on $F_{j}$. Changes in $F_{j}$ have a direct causal interpretation as the data are drawn from these distributions. In empirical economics it is the industry standard to estimate $F_{j}$ directly by imposing various assumptions on it and on the dependence structure to achieve identification. In this paper we follow a different approach, where we first estimate $Q_{j}$ and then estimate the bounds for $F_{j}$ without imposing any direct parametric assumptions on it.

The dependence structure between risks is determined by the copula $C\left(f_{1}, \ldots, f_{5} ; \mathbf{x}\right)=P\left(f_{1} \leq\right.$ $\left.F_{1}, \ldots, f_{5} \leq F_{5} ; \mathbf{x}\right)$, the joint distribution of the ranks of the duration variables. Knowledge of the copula function ensures identifiability of $F_{j}(t ; \mathbf{x})$, while if it is unknown, only bounds for $F_{j}(t ; \mathbf{x})$ can be determined. For the nonparametric model these bounds were derived by Peterson (1976). Due to the non-identifiability of the competing risks model, the copula cannot be estimated and assuming the wrong copula leads to biased estimators for $F_{j}(t ; \mathbf{x})$. While being biased, they still fall into the Peterson bounds and depending on the assumed dependence structure, 
any point in the Peterson bounds can be attained. Applied econometric research often assumes independence between risks. In this case standard estimators such as the Kaplan-Meier estimator or the Cox proportional hazard model (Cox, 1962) can be applied. The mixed proportional hazard (or frailty) model assumes a La-Place copula which belongs to the family of Archimedean copulas (Oakes, 1989, Lo and Wilke, 2010). Moreover, (mixed) proportional hazard models impose direct functional form assumptions on $F_{j}(t ; \mathbf{x})$ and they assume that the copula is independent of $\mathbf{x}$ (Bond and Shaw, 2006).

In this paper, we avoid direct assumptions on $F_{j}(t ; \mathbf{x})$ as they are hard to verify. We consider a special case of the regression model of Lo and Wilke (2011). They show identifiability of $F_{j}(t ; \mathbf{x})$ if the copula is Archimedean, known and independent of $\mathbf{x}$. The model in this paper is a special case of their model, because we assume a semi-parametric $Q_{j}(t ; \mathbf{x})$ and we assume that the copula is a Frank copula with one unknown parameter. This is done for tractability reasons, because the parameter is unknown and determines the sensitivity of estimation results rather than assuming a specific value, e.g. independence of risks. We estimate the model on a grid on the support of the copula parameter to determine bounds for the functionals of interest $\left(F_{j}(t ; \mathbf{x})\right)$ which are then used to bound the treatment effect of the policy reform. The merit of our approach is that we obtain bounds which reflect the non-identifiability of the competing risks model.

While the Frank copula is a special case of an Archimedean copula, it is generally known in copula modelling that the functional form of the copula is often less important for the results than restricting the degree of correlation between risks. For example, Rivest and Wells (2001) find in a simulation study that the bias caused by misspecifying the degree of correlation is 3.6 times larger than the bias caused by misspecifying the parametric form of the Archimedean copula. Zheng and Klein (1995) find similar results in a sensitivity study and confirm that using a wrong family of Archimedean copula produces little difference of estimates while using a wrongly assumed degree of correlation between risks generates considerable bias. Including other Archimedean copulas into our sensitivity might result in wider bounds for $F_{j}(t ; \mathbf{x})$.

The Frank copula has the nice feature that - depending on its parameter - the correlation between the competing risks can be highly positive and highly negative with independence as a special case. The correlation is measured by the so called Kendall $\tau$, which is in $[-1,1]$ in the case of the Frank copula (see Nelsen, 2006, for more details on copula functions). As there is a 1-1 relationship between $\tau$ and the copula parameter, we only refer here to $\tau$. Depending on the 
value of $\tau$, application of the Copula Graphic Estimator yields

$$
\tilde{F}_{j}(t ; \mathbf{x}, \tau)=1-\xi_{\tau}^{-1}\left[-\int_{0}^{t} \xi_{\tau}^{\prime}\left(1-\sum_{j=1}^{5} Q_{j}(u ; \mathbf{x})\right) Q_{j}^{\prime}(u ; \mathbf{x}) d u\right],
$$

where $\xi_{\tau}($.$) is the so-called copula generator of the Frank copula and we have \tilde{F}_{j}=F_{j}$ for the true value of $\tau$. Depending on the choice of $\tau$, the resulting $\tilde{F}_{j}(t ; \mathbf{x}, \tau)$ can attain any point in the identification set for $F_{j}$. We determine the identification set by $F_{j}(t ; \mathbf{x}) \in\left[\underline{F}_{j}(t ; \mathbf{x}), \bar{F}_{j}(t ; \mathbf{x})\right]$ with $\underline{F}_{j}(t ; \mathbf{x})=\min _{\tau} \tilde{F}_{j}(t ; \mathbf{x}, \tau)$ and $\bar{F}_{j}(t ; \mathbf{x})=\max _{\tau} \tilde{F}_{j}(t ; \mathbf{x}, \tau)$ on a 0.05 grid for $\tau \in[-0.95,0.95]$.

Due to the design of the policy reform under investigation, we apply a difference-in-differences (DiD) approach for the identification of the reform effect. In particular, we assess the effect of the reform by determining $\Delta_{j}(t ; \overline{\mathbf{x}})$, the change in $F_{j}(t ; \mathbf{x})$ at the sample means of the covariates, $\overline{\mathbf{x}}$ as follows:

$$
\begin{aligned}
\Delta_{j}(t ; \overline{\mathbf{x}})= & F_{j}(t ; P=1, G=1, \overline{\mathbf{x}})-F_{j}(t ; P=0, G=1, \overline{\mathbf{x}}) \\
& -\left(F_{j}(t ; P=1, G=0, \overline{\mathbf{x}})-F_{j}(t ; P=0, G=0, \overline{\mathbf{x}})\right)
\end{aligned}
$$

with $P$ is the post reform period dummy and $G$ is the treatment group dummy. $G$ and $P$ do not belong to the regressor set as the $F_{j}$ s are determined separately conditional on $P$ and $G$. As $F_{j}$ is not identified but bounded, also $\Delta_{j}(t ; \overline{\mathbf{x}})$ can only be bounded by $\Delta_{j}(t ; \overline{\mathbf{x}}) \in\left[\underline{\Delta}_{j}(t ; \overline{\mathbf{x}}), \bar{\Delta}_{j}(t ; \overline{\mathbf{x}})\right]$ with

$$
\begin{aligned}
\Delta_{j}(t ; \overline{\mathbf{x}})= & \max \left[\underline{F}_{j}(t ; P=1, G=1, \overline{\mathbf{x}})-\bar{F}_{j}(t ; P=0, G=1, \overline{\mathbf{x}})\right. \\
& \left.-\left(\bar{F}_{j}(t ; P=1, G=0, \overline{\mathbf{x}})-\underline{F}_{j}(t ; P=0, G=0, \overline{\mathbf{x}})\right),-1\right] \\
\bar{\Delta}_{j}(t ; \overline{\mathbf{x}})= & \min \left[\bar{F}_{j}(t ; P=1, G=1, \overline{\mathbf{x}})-\underline{F}_{j}(t ; P=0, G=1, \overline{\mathbf{x}})\right] \\
& \left.-\left(\underline{F}_{j}(t ; P=1, G=0, \overline{\mathbf{x}})-\bar{F}_{j}(t ; P=0, G=0, \overline{\mathbf{x}})\right), 1\right]
\end{aligned}
$$

This produces the identification bounds for the treatment effect in absence of restrictions on the dependence structure other than having assumed a Frank copula with unknown parameter that is independent of the regressors. $\Delta_{j}(t ; \overline{\mathbf{x}})$ is bounded by -1 and 1 as $F_{j}$ cannot change by more than 1. If the lower (upper) bound is greater (smaller) than zero, we have identified the direction of the treatment effect. This would provide evidence for a left (right) shift of $F_{j}$ in response to the shortening of the unemployment benefit entitlement lengths.

As these worst case bounds might be rather wide in applications and therefore may not even reveal the direction of the treatment effect, we propose an independence assumption as an attempt 
to tighten the bounds. In particular, we assume that $C\left(f_{1}, \ldots, f_{5} ; P, G\right)=C\left(f_{1}, \ldots, f_{5}\right)$, i.e. the dependence structure is the same for the treatment and control group and the pre-reform and post-reform period. This assumption, however, is still weaker than what the conventional duration models assume. Under this assumption, the DiD changes can be computed for all values of $\tau$. In particular, we compute

$$
\begin{aligned}
\tilde{\Delta}_{j}(t ; \overline{\mathbf{x}}, \tau)== & \tilde{F}_{j}(t ; P=1, G=1, \overline{\mathbf{x}}, \tau)-\tilde{F}_{j}(t ; P=0, G=1, \overline{\mathbf{x}}, \tau) \\
& -\left(\tilde{F}_{j}(t ; P=1, G=0, \overline{\mathbf{x}}, \tau)-\tilde{F}_{j}(t ; P=0, G=0, \overline{\mathbf{x}}, \tau) .\right)
\end{aligned}
$$

and the lower and upper bound for the treatment effect are now given by:

$$
\begin{aligned}
\Delta_{j}^{I}(t ; \overline{\mathbf{x}}) & =\min _{\tau} \tilde{\Delta}_{j}(t ; \overline{\mathbf{x}}, \tau) \\
\bar{\Delta}_{j}^{I}(t ; \overline{\mathbf{x}}) & =\max _{\tau} \tilde{\Delta}_{j}(t ; \overline{\mathbf{x}}, \tau),
\end{aligned}
$$

with $\Delta_{j}^{I}(t ; \overline{\mathbf{x}}) \leq \bar{\Delta}_{j}^{I}(t ; \overline{\mathbf{x}})$. It can be easily verified that $\Delta_{j}(t ; \overline{\mathbf{x}}) \leq \Delta_{j}^{I}(t ; \overline{\mathbf{x}}) \leq \bar{\Delta}_{j}^{I}(t ; \overline{\mathbf{x}}) \leq \bar{\Delta}_{j}(t ; \overline{\mathbf{x}})$, but it remains an empirical exercise to determine by how much the bounds are tightened.

In practice, estimation takes place in two steps. In the first stage, a proportional hazard model for $Q_{j}$ is estimated (Fine and Gray, 1999) using the stata-module stcrreg. In the second stage, we utilize first stage results under the assumption of the Frank copula to estimate $\tilde{F}_{j}$ (Lo and Wilke, 2011). In our application, $Q_{j}$ in equation (1) are replaced by their sample analogues which will then determine the estimator for $\tilde{F}_{j}$. The latter are then used to obtain the bounds for the treatment effect in equations (2) - (5). As the model of Lo and Wilke (2011) requires continuity of $Q_{j}(t ; \mathbf{x})$ in $t$, we apply a local polynomial Kernel smoother to the estimate of the baseline cumulative incidence. Working with discontinuous $Q_{j}$ would produce numerical problems and can result in implausible jumps in the estimates for $\tilde{F}_{j}$. All estimations were performed with Stata $11 \mathrm{MP}$.

As has already been mentioned in Section 3, we have a missing data problem for time periods that were not covered by the administrative data. The data only provide information about the lower and upper bound for the true unemployment duration. Arntz et al. (2008) develop bounds for $Q_{j}$ resulting from partially observed unemployment durations. While for bounding $Q_{j}$ it suffices to consider the lower and upper bound for the unemployment duration, this is not the case for $\tilde{F}_{j}$. Suppose we can only observe a lower bound and upper bound of the true unemployment duration in the data, which we denote as $a$ and $b$, respectively. Then we have $Q_{j}^{a} \leq Q_{j} \leq Q_{j}^{b}$ but this does 
not imply that $\tilde{F}_{j}^{a} \leq \tilde{F}_{j} \leq \tilde{F}_{j}^{b}$ (see equation (2) in Lo and Wilke 2011). We have also tested this empirically and observed a number of rejections of the monotonicity for the data bound for $\tilde{F}_{j}$. For this reason, we do not construct double bounds which combine the problem of partially identified interval data (Lee and Wilke, 2009) and the nonidentifability of the model (Cox, 1962, Tsiatis, 1975). While a sensitivity analysis in the definition of unemployment produced very similar point estimates, this does not reveal the endpoints for the data bounds for the treatment effect.

Due to the flexibility of our model for $Q_{j}$, the asymptotic covariance matrix for $Q_{j}$ is unknown except for the variance of the estimator for $\beta$ (Fine and Gray, 1999). Because each $F_{j}$ in our model depends on all $Q_{j}$ (see Lo and Wilke, 2011, for details), the asymptotic distribution for $F_{j}$ is unknown, too. For this reason, we apply the bootstrap to determine confidence intervals for the estimator for $\tilde{F}_{j}(t ; \mathbf{x}, \tau)$ and $\tilde{\Delta}_{j}(t ; \overline{\mathbf{x}}, \tau)$. Due to capacity constraints, it was not feasible for us to obtain confidence intervals for the estimated $\underline{\Delta}_{j}(t ; \overline{\mathbf{x}})$ and $\bar{\Delta}_{j}(t ; \overline{\mathbf{x}})$ as they are determined by all values of $\tau$. For this reason, we only present confidence intervals for the estimated $\tilde{\Delta}_{4}(t ; \overline{\mathbf{x}}, \tau)$ for two values of $\tau$ in Figure 5 in the Appendix. It is apparent that the uncertainty due random sampling is less important than the uncertainty about the true value of $\tau$. While this is supportive for our approach to mainly focus on the non-identifiability, the confidence intervals appear to be rather wide given the large sample size. Moreover, it is briefly remarked that the bounds in our framework are sharp.

\section{Results}

We first briefly discuss first stage estimation results for the subdistribution regressions before we present the estimated bounds for the reform effect on $F_{j}$. Figure 1 displays the estimated cumulative incidence curves $Q_{j}$ at the sample mean of the regressors for previous low-wage earners (a) and for previous non low-wage earners (b). Figure 2 presents the DiD estimator for the changes in cumulative incidence with $95 \%$ bootstrap confidence intervals for both groups. A positive (negative) DiD estimator can be interpreted as a upward (downward) shift of the subdistribution function $Q_{j}$.

The results in Figure 1 differ from the information in Table 2 by controlling for the observable characteristics and exceed it by providing information for all durations. Similar to the descriptive evidence, we observe that previous (non) low-wage earners are mostly inclined to take up (non) low- 
Figure 1: Estimated cumulative incidences at the mean of the regressors.

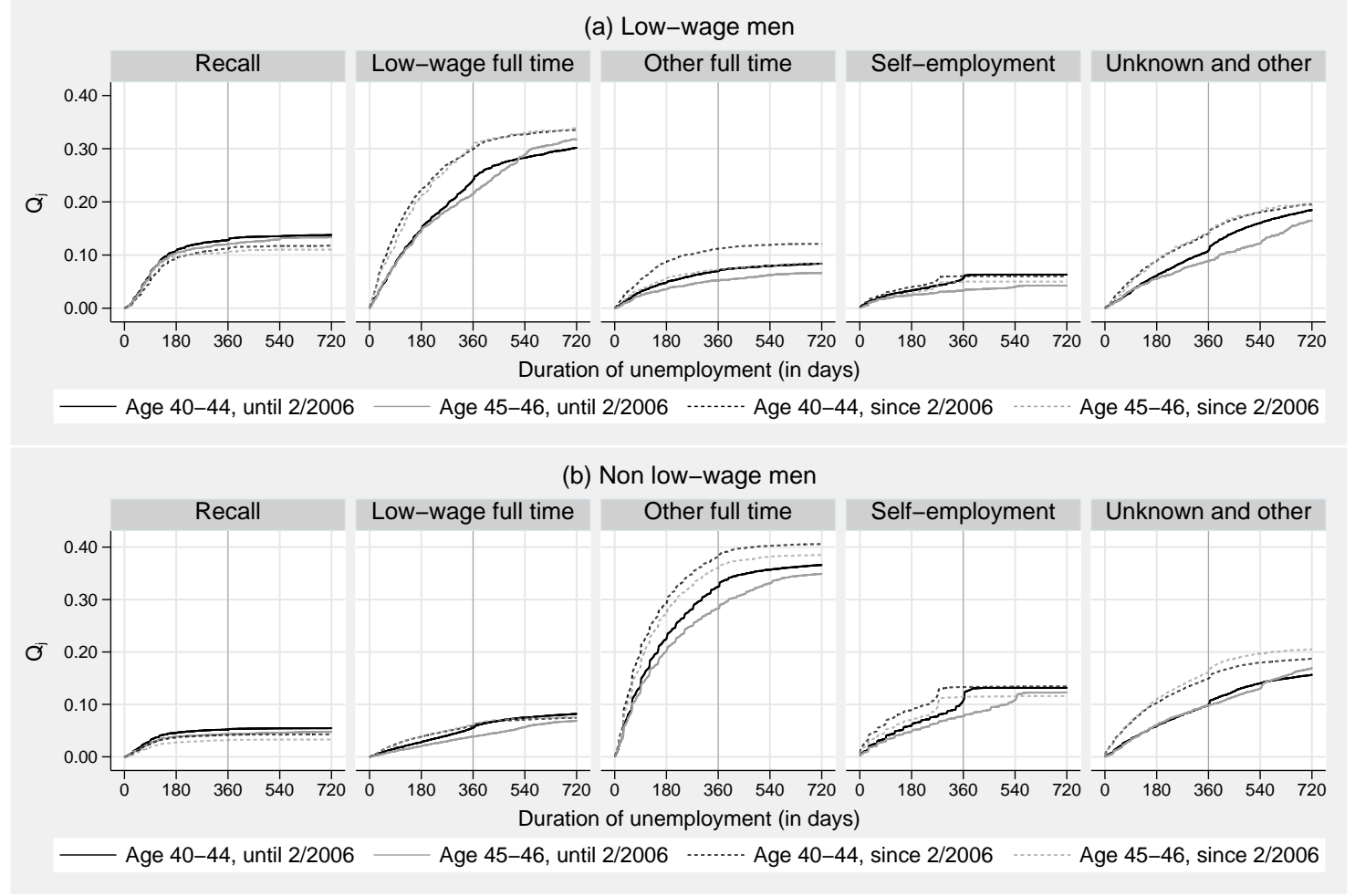

wage employment. The observed probability to experience a recall is higher for low-wage workers and for both groups there is hardly any recall after 6 month of unemployment. The observed probability to take up subsidized self-employment is higher for non low-wage workers than for the low-wage group. Figure 2 suggests considerable changes in subdistributions. In particular for non low-wage males, subdistributions shift to the right for all risks except for recalls. For subsidized self-employment the shift is observed only during the treatment period. The estimated changes for the non-low wage males are mainly significant during the treatment period, while for low-wage males they often lack of statistical significance. Still there is some evidence for a left shift in the cumulative incidence for low-wage employment at the start of the treatment period. We also observe a right shift in the cumulative incidence for other full- time employment for most durations. While this relates to observed transitions, it remains unclear at this stage if this surprising pattern is also present for changes in the marginal distributions.

We have estimated in total 40 regressions for the two wage and age groups, the two time periods, and the five risks. Tables 5-9 in the Appendix present the estimated hazard ratios of the semiparametric proportional hazard subdistribution model (Fine and Gray 1999). In many cases the hazard ratios vary across groups and risks, which motivates our stratified competing risks 
Figure 2: Difference-in-Differences estimator for changes in $Q_{j}$ at the mean of the regressors with $95 \%$ bootstrap confidence bands.

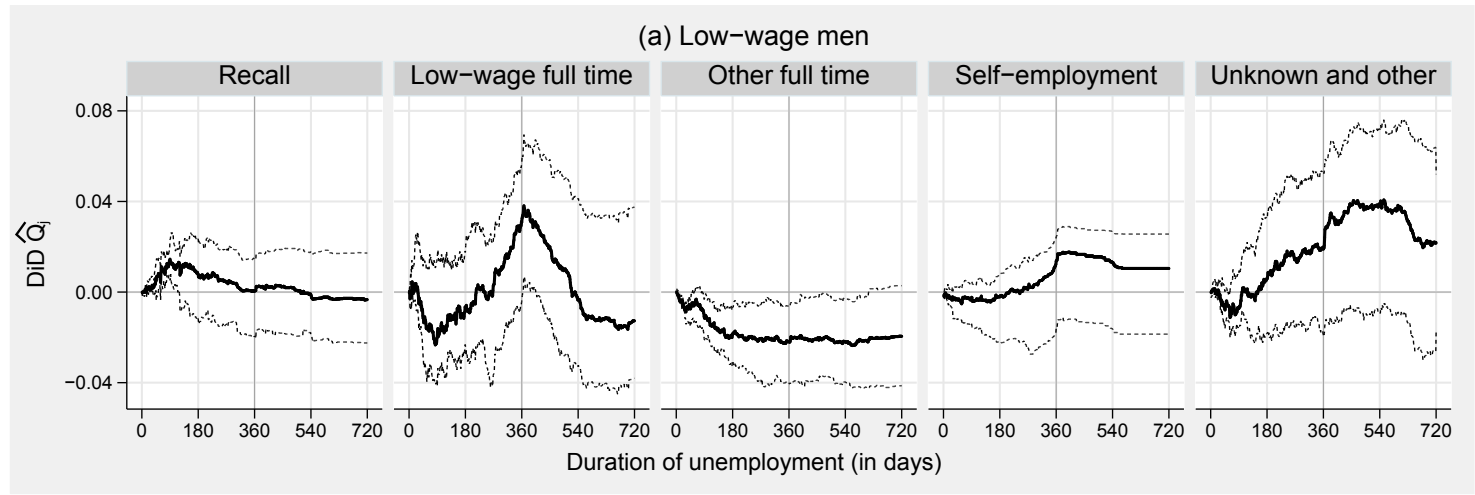

(b) Non low-wage men

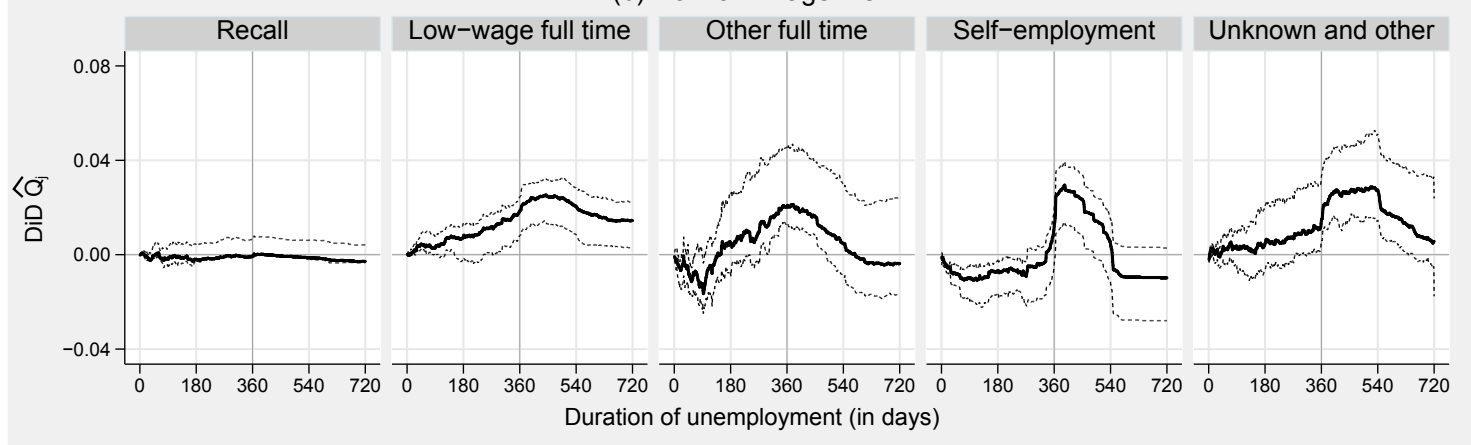

approach. The results also reveal a number of interesting strong statistical relationships between the observable covariates and the observed transitions into the five states. As the amount of information in these tables is too big to be described in detail, we only provide a brief summary of the main findings:

- For recalls we observe that white collar workers have an around 10-70\% lower subdistribution hazard rate than unskilled blue collar workers, everything else equal. Unemployed who have already experienced a recall out of unemployment in the past have a $60-190 \%$ higher hazard. If an unemployed participated already in a labor market program during a foregoing unemployment spell, the hazard for being recalled is 20-30\% lower. Observing a recall in agriculture is much more common than in other business sectors with the hazard being twice to four times higher than in manufacturing, while it is also higher (often 30-60\%) for temporary work agencies.

- For transitions into low-wage employment, we observe some differences across previously lowwage and non low-wage workers. Educated or skilled workers with non low pre-unemployment 
earnings have a $20-50 \%$ lower hazard to take up a low-wage job; a lack of skills and formal education makes it therefore much less likely to leave the low paid sector. Previously low-wage workers who have already experienced a recall in the past have a lower hazard to take-up a low-wage job at another employer (20-40\%). If the last job was in agriculture (compared to manufacturing), it is less likely to observe a transition to a low paid job (10-60\% lower hazard). Unemployed with a non low-paid work history who were working in a larger firm (more than 50 employees), have a 20-70\% higher risk to accept a low-wage job than those who have been working in smaller firms. The hazard to take up a low-wage job is up to twice as high in Eastern Germany compared to Western Germany.

- For non low-wage employment, we observe that skills and formal education greatly increase the hazard of a transition. For unemployed with an university degree it is up to $190 \%$ higher compared to those with a low education, and it is often $30 \%$ higher for skilled or white collar workers compared to an unskilled without formal qualification. The risk to enter a non-low wage job is up to $40 \%$ lower if the unemployed had been recalled in the past. Furthermore, the hazard for observed transitions into non low-paid employment is up to $50 \%$ lower in Eastern Germany, and it is up to $150 \%$ higher in particular West German states (compared to Nordrhein-Westfalen) for previously low-wage workers.

- The hazard to take up subsidized self-employment is $80-220 \%$ higher for white collar workers. It is mostly lower in agriculture than in manufacturing, but $20-130 \%$ higher if the last job has been in financial or public services. If the unemployed was previously employed in a large firm, the hazard is often 30-50\% lower, suggesting a negative relationship between firm size and entrepreneurial activity of (previous) employees.

While the results in Figure 2 suggest that the reform under investigation lead to various changes in $Q_{j}$, it remains unclear whether this is also true for $F_{j}$. Figure 3 presents estimated lower and upper bounds for $\Delta_{j}$ given by equations (2) and (3), for low (Panel A) and non low preunemployment wage (Panel b). In order to provide a familiar comparison benchmark for these bounds, we also plot $\hat{\Delta}_{j}$ when $F_{j}$ has been directly estimated by the Cox proportional hazard regression. The sign of the treatment is identified if $\hat{\bar{\Delta}}_{j}$ (or $\hat{\Delta}_{j}$ ) is less (or greater) than zero. It is apparent that the bounds are very wide and therefore uninformative about the direction of the effect. This finding is new for applied research as previous analysis operated under stronger 
assumptions on the dependence structure to achieve identification.

Figure 3: Estimated $\underline{\Delta}_{j}$ and $\bar{\Delta}_{j}$ at the mean of the regressors.

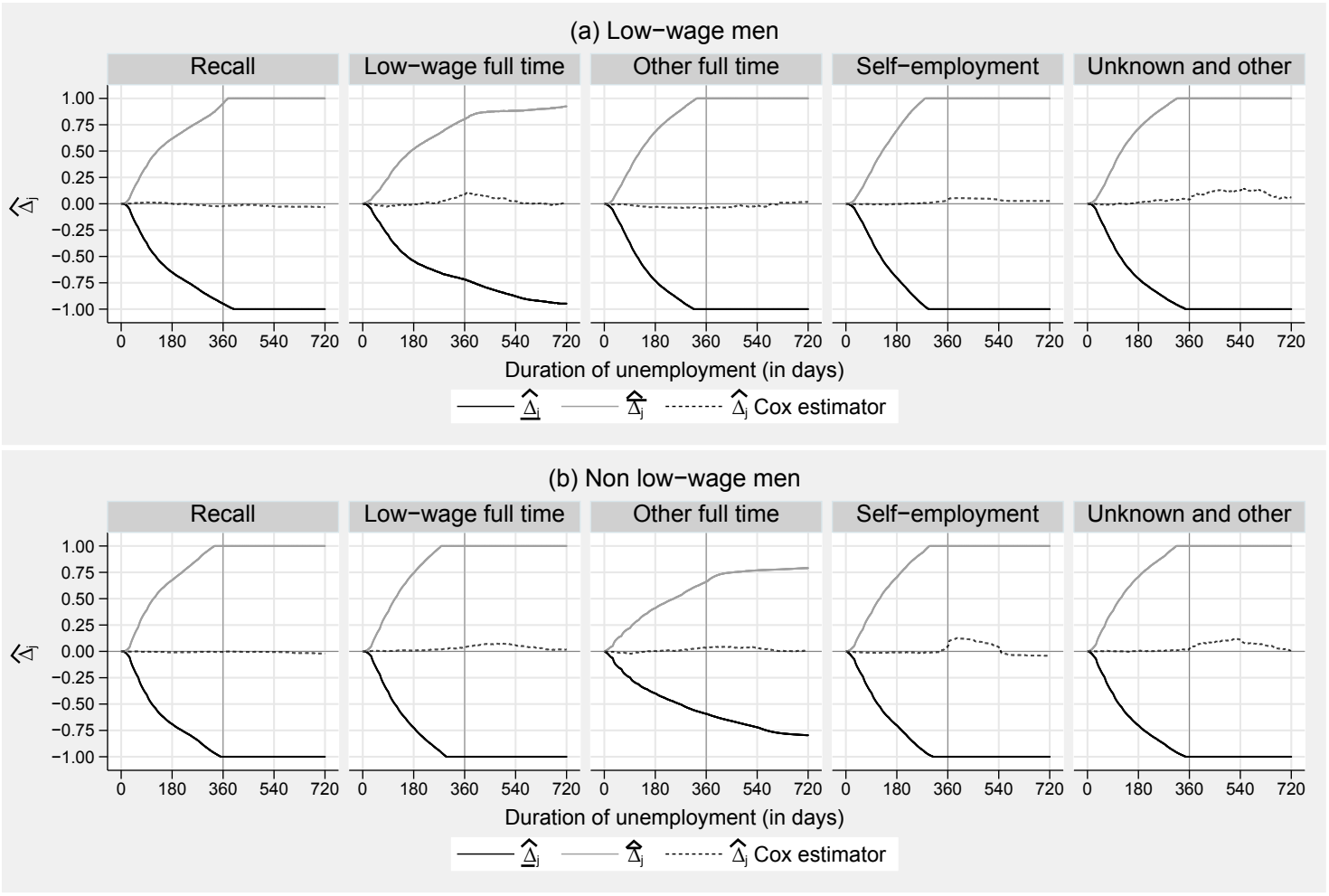

Estimates for $\Delta_{j}^{I}(t ; \overline{\mathbf{x}})$ and $\bar{\Delta}_{j}^{I}(t ; \overline{\mathbf{x}})$ (under the assumption that the copula is independent of groups and periods) are presented in Figure 4. These bounds are much tighter and in most cases they reveal the direction of the treatment effect. As a comparison, we also plot the Cox model estimate for the treatment effect. As it is apparent from the figure, in most cases the Cox estimator lies within our identification bounds. It can fall outside because the Cox model imposes a different structure on $F_{j}$ than our model but it is not due to the assumption of a Frank copula in our model (our dependence structure contains independent risks as a special case). If Cox estimates do not fall into our bounds, it is likely that the two do not differ statistically (compare Figure 5 in the Appendix for the size of the confidence bands).

For previously low-wage workers, the estimated bounds indicate a right shift of $F_{j}$ for subsidized self-employment and low-wage jobs, the latter peaking around the start of the treatment. The observed right shift of the cumulative incidence for other full-time jobs is less clear for the marginal distribution, although there evidence for a right shift between 3 and 9 months but it is unlikely to be statistically significant given the size of the confidence intervals in Figure 2a). 
Figure 4: Estimated $\Delta_{j}^{I}$ and $\bar{\Delta}_{j}^{I}$ at the mean of the regressors.

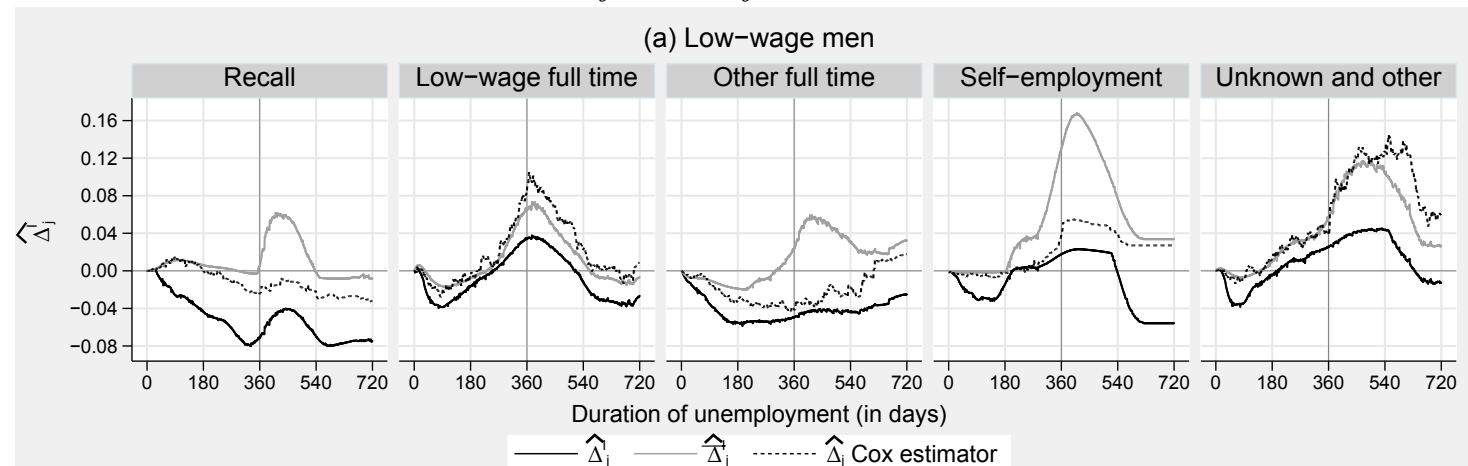

(b) Non low-wage men

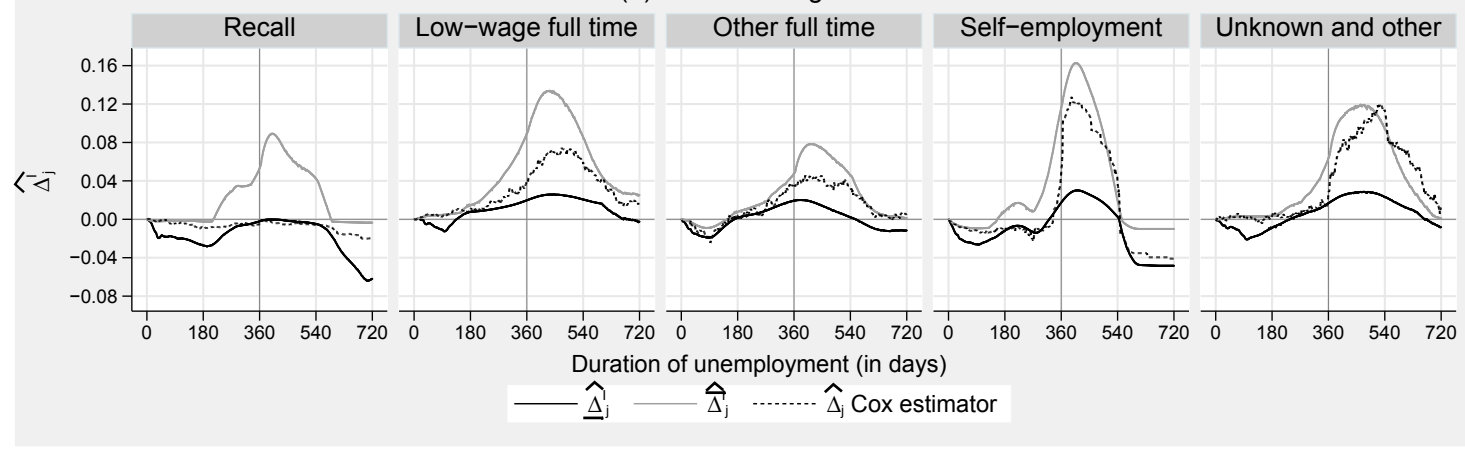

For previously non low-wage workers we observe a right shift of $F_{j}$ for almost every risk (excepted recalls), which give some support that this group reacts in response to shorter benefit entitlements. We find also that timings of the peak of the treatment effect vary across risks. While it seems to be at or shortly after expiration of benefits for the risks other full-time employment and subsidized self-employment and the upper bound for recall, it is a bit later for low-wage employment. This might indicate for transitions into the first two states that there is some strategic waiting until benefits are about to expire, while taking up a low-wage job becomes more likely some time after benefits have been expiring. Figure 5 in the appendix suggests that the peak of effects for the non low-wage males can be well significantly different from zero. The most important changes in $F_{j}$ in response to the reform can be identified for the risk subsidized self-employment, where marginal distribution function increases by $3-16$ percentage points in response to the shortening of the benefit entitlement lengths. Given that the sample average of transitions into this state is less than $15 \%$, it is indeed a potentially sizeable effect. Further reform effects can be identified for the group of previous non low-wage earners. For the risks to enter non low-wage and low-wage employment, the effect turns positive after less than half a year of unemployment duration. This 
suggests that the job taking speed of this group increases already before entitlements have expired.

We conducted a number of robustness checks in an attempt to detect possible instability of our results. Some of them have already been mentioned in the course of the paper. We run additional estimations by changing (extending, removing) the anticipation period. We vary the definition of the control group (aged 43-44 instead of 40-44) and take a legal change in self employment subsidies into account. We also used another definition of unemployment, encompassing also times with missing information in the data. We do not obtain evidence for instability of our main result pattern for the reform effects. We also estimated placebo reform effects within the preand post-reform period for all men. Most of the bounds of the placebo effects are narrow and close to zero. Although the bounds for the placebo effects are sometimes greater than zero, it is unlikely that these changes are significant due to the reduced sample size. We also estimated the effects for a different treatment group (aged 47-51) which has a different treatment intensity and possibly stronger anticipation behavior. As we would expect for this group there is some evidence for larger effects (as long as they exist) for the non low wage males but results patterns are rather similar across the line. The results of these checks are provided in supplementary material of this paper.

\section{Summary and Policy Implications}

Our analysis uses an innovative approach to address a frequently analyzed problem in economics. It takes into account the non-identifiability of the competing risks model and produces bounds for quantities of interest which reflect this model feature. Surprisingly we obtain evidence that the resulting identification bounds for the treatment effect are very wide and preclude any informative result despite having access to very large and comprehensive individual administrative data. This is an important finding which was 'assumed away' in previous studies which focused on identified models under stronger assumptions on the dependence structure or marginal distributions. After assuming that the dependence structure between risks is the same for our treatment and control group before and after the reform, the identification bounds become much tighter and often reveal the sign of the treatment effect. Still, the exact magnitude of the effect is difficult to assess due to the non-identifiability of the model. As a result, any changes in expected unemployment durations can only be bounded. 
Due to the availability of rich data, we are able to present a number of unprecedented insights how the unemployment benefit system affects the duration of unemployment. While previous analysis for Germany has mainly focused on exits to employment, we have enough observations to distinguish between recalls, low-wage jobs and non low-wage jobs. Moreover, we consider subsidized firm creation as an additional highly policy relevant risk.

Our results are important for policy makers in many countries with a similarly designed unemployment compensation system. Contribution based unemployment benefits, whose level are dependent on the pre-unemployment income, affect the labor market outcomes of previous non low-wage individuals. They are thus "nice to have" for individuals who do not pass means tests. The strength of the effect varies, however, strongly across risks and to some extent by pre unemployment wage level. We identify an - potentially large - increase in the probability of entering full-time employment for non low-wage males, something probably intended and desired by the reform. We are not able to identify an effect for the distribution of recalls, which is probably due to the fact that most recalls occur within a six-months-period anyway. Our results therefore do not provide evidence that there is strategic waiting until unemployment benefits are exhausted before a recall offer is made and accepted. The evidence for sizable effects on the desired destination states is therefore limited, although they may exist but cannot be revealed due to the non-identifiability of the model. Our results therefore do not unambiguously show that shorter benefit entitlements drastically increase job taking probabilities. We also find indications that the increase in transitions into low paid employment - something less desirable for previously higher earners - potentially increases strongly. Also, this effect steps in some time after expiration of benefits and therefore later than for higher paid employment. This indicates that taking up a low paid job might be less due to strategic waiting but more due to a lack of better paid alternatives after benefits have expired. This might also have effects on the quality of matches.

This is in contrast to the timing of firm-foundation out of unemployment. The probability distribution of starting a claim of self-employment subsidy clearly reacts on the expiration date of unemployment benefits, with a "mass point" in the distribution at the time of expiration. Our results therefore suggest that these subsidies may have been to some extent used as a follow up funding for unemployed who would loose benefit entitlements otherwise. Indeed, the institutional setup in Germany is to some extent encouraging free riding, as the eligibility for self-employment subsidies is not means tested and has to be granted by law if the business plan satisfies some 
minimum standards. The design of the self-employment subsidies for unemployed in Germany therefore casts some doubts whether all start-ups had occurred in response to a promising business idea. It partly might have been an easy way for unemployed to increase household income once benefits have expired. A labor market reform in Germany enacted at the beginning of 2012 altered access conditions to subsidized self-employment by requiring 150 days (instead of 30 days) of remaining unemployment benefit claims and shortening the duration of subsidization to 6 months (instead of 9 months). This implies that subsidized self-employment prolonges unemployment benefit receipt by only one month and would therefore make the subsidy much less financially attractive. Of course, this will probably come at the "expense" of lower firm creation rates and higher unemployment rates as self-employed do not appear in the unemployment figures. 
Appendix 
Table 3: Sample means of variables by age group and time period

\begin{tabular}{|c|c|c|c|c|c|c|c|c|c|c|}
\hline \multirow{3}{*}{$\begin{array}{l}\text { Group } \\
\text { Age } \\
\text { Time period }\end{array}$} & \multicolumn{5}{|c|}{ Low-wage males } & \multicolumn{5}{|c|}{ Non low-wage males } \\
\hline & \multirow{2}{*}{$\begin{array}{r}40-46 \\
\text { Both }\end{array}$} & \multicolumn{2}{|c|}{$40-44$} & \multicolumn{2}{|c|}{$45-46$} & \multirow{2}{*}{$\begin{array}{r}40-46 \\
\text { Both }\end{array}$} & \multicolumn{2}{|c|}{$40-44$} & \multicolumn{2}{|c|}{$45-46$} \\
\hline & & Pre & Post & Pre & Post & & Pre & Post & Pre & Post \\
\hline \multicolumn{11}{|l|}{ Individual characteristics } \\
\hline Low education & 0.08 & 0.07 & 0.09 & 0.06 & 0.08 & 0.04 & 0.04 & 0.04 & 0.03 & 0.05 \\
\hline Vocational training or Abitur & 0.87 & 0.88 & 0.86 & 0.89 & 0.86 & 0.76 & 0.76 & 0.75 & 0.77 & 0.76 \\
\hline University & 0.05 & 0.04 & 0.05 & 0.05 & 0.05 & 0.20 & 0.20 & 0.21 & 0.20 & 0.20 \\
\hline Unskilled blue collar & 0.47 & 0.45 & 0.51 & 0.42 & 0.49 & 0.27 & 0.27 & 0.27 & 0.26 & 0.27 \\
\hline Skilled blue collar & 0.40 & 0.43 & 0.34 & 0.46 & 0.38 & 0.28 & 0.29 & 0.26 & 0.31 & 0.28 \\
\hline White collar & 0.13 & 0.12 & 0.15 & 0.12 & 0.13 & 0.45 & 0.43 & 0.47 & 0.43 & 0.45 \\
\hline Married & 0.55 & 0.55 & 0.51 & 0.61 & 0.56 & 0.63 & 0.63 & 0.59 & 0.68 & 0.65 \\
\hline Non-German & 0.18 & 0.17 & 0.21 & 0.15 & 0.17 & 0.12 & 0.12 & 0.13 & 0.11 & 0.13 \\
\hline \multicolumn{11}{|l|}{ During last 7 years } \\
\hline Years of employment & 5.52 & 5.40 & 5.45 & 5.90 & 5.89 & 6.24 & 6.17 & 6.21 & 6.40 & 6.48 \\
\hline Years of tenure at last employer & 3.21 & 3.10 & 3.10 & 3.66 & 3.66 & 3.58 & 3.48 & 3.54 & 3.78 & 3.87 \\
\hline Years of unemployment & 0.71 & 0.68 & 0.89 & 0.44 & 0.60 & 0.28 & 0.30 & 0.33 & 0.20 & 0.18 \\
\hline Number of employers & 2.79 & 2.86 & 2.87 & 2.54 & 2.51 & 2.55 & 2.62 & 2.58 & 2.42 & 2.36 \\
\hline Past recall & 0.19 & 0.19 & 0.20 & 0.20 & 0.19 & 0.14 & 0.14 & 0.14 & 0.15 & 0.14 \\
\hline $\begin{array}{l}\text { Past labor market program } \\
\text { Characteristics last job }\end{array}$ & 0.35 & 0.35 & 0.40 & 0.25 & 0.33 & 0.20 & 0.19 & 0.24 & 0.16 & 0.19 \\
\hline Daily wage rate & 43.30 & 43.40 & 43.00 & 43.75 & 43.23 & 95.62 & 92.71 & 98.69 & 94.18 & 99.55 \\
\hline Manufacturing & 0.21 & 0.23 & 0.18 & 0.23 & 0.19 & 0.36 & 0.38 & 0.33 & 0.39 & 0.36 \\
\hline Agriculture, mining, energy & 0.06 & 0.06 & 0.06 & 0.07 & 0.07 & 0.03 & 0.03 & 0.03 & 0.03 & 0.03 \\
\hline Retail sector & 0.17 & 0.16 & 0.17 & 0.17 & 0.18 & 0.20 & 0.19 & 0.22 & 0.19 & 0.20 \\
\hline Hotels and restaurants & 0.09 & 0.08 & 0.11 & 0.07 & 0.09 & 0.02 & 0.01 & 0.02 & 0.01 & 0.02 \\
\hline Transport sector & 0.14 & 0.14 & 0.15 & 0.14 & 0.16 & 0.09 & 0.08 & 0.10 & 0.09 & 0.10 \\
\hline Economic and financial services & 0.13 & 0.13 & 0.14 & 0.12 & 0.16 & 0.17 & 0.16 & 0.18 & 0.16 & 0.17 \\
\hline Public services & 0.08 & 0.08 & 0.08 & 0.08 & 0.08 & 0.11 & 0.12 & 0.11 & 0.12 & 0.11 \\
\hline Temporary agency sector & 0.11 & 0.12 & 0.11 & 0.12 & 0.08 & 0.02 & 0.02 & 0.02 & 0.02 & 0.02 \\
\hline Firm size up to 50 & 0.67 & 0.67 & 0.66 & 0.67 & 0.67 & 0.52 & 0.54 & 0.51 & 0.53 & 0.50 \\
\hline Firm size $51-100$ & 0.17 & 0.17 & 0.16 & 0.18 & 0.15 & 0.17 & 0.17 & 0.16 & 0.17 & 0.16 \\
\hline Firm size $101-250$ & 0.11 & 0.10 & 0.12 & 0.09 & 0.11 & 0.14 & 0.13 & 0.14 & 0.13 & 0.13 \\
\hline Firm size 251 and more & 0.06 & 0.06 & 0.06 & 0.05 & 0.07 & 0.18 & 0.16 & 0.19 & 0.16 & 0.20 \\
\hline \multicolumn{11}{|l|}{ Federal state } \\
\hline Nordrhein-Westfalen & 0.22 & 0.21 & 0.22 & 0.23 & 0.24 & 0.27 & 0.27 & 0.27 & 0.26 & 0.26 \\
\hline Schleswig-Holstein/Hamburg & 0.04 & 0.04 & 0.04 & 0.04 & 0.04 & 0.06 & 0.06 & 0.06 & 0.06 & 0.05 \\
\hline Niedersachsen/Bremen & 0.08 & 0.08 & 0.09 & 0.05 & 0.08 & 0.11 & 0.11 & 0.11 & 0.10 & 0.11 \\
\hline Hessen & 0.05 & 0.05 & 0.05 & 0.04 & 0.06 & 0.08 & 0.08 & 0.08 & 0.08 & 0.08 \\
\hline Rheinland-Pfalz/Saarland & 0.04 & 0.04 & 0.05 & 0.03 & 0.04 & 0.06 & 0.06 & 0.06 & 0.06 & 0.07 \\
\hline Baden-Württemberg & 0.06 & 0.06 & 0.07 & 0.06 & 0.08 & 0.13 & 0.13 & 0.13 & 0.12 & 0.13 \\
\hline Bayern & 0.09 & 0.08 & 0.09 & 0.08 & 0.09 & 0.15 & 0.15 & 0.15 & 0.16 & 0.16 \\
\hline Brandenburg/Berlin & 0.14 & 0.15 & 0.13 & 0.14 & 0.12 & 0.06 & 0.07 & 0.06 & 0.06 & 0.06 \\
\hline Mecklenburg-Vorpommern & 0.06 & 0.07 & 0.05 & 0.08 & 0.06 & 0.02 & 0.02 & 0.02 & 0.02 & 0.02 \\
\hline Sachsen & 0.14 & 0.14 & 0.12 & 0.16 & 0.13 & 0.04 & 0.04 & 0.04 & 0.04 & 0.04 \\
\hline Sachsen-Anhalt & 0.08 & 0.09 & 0.07 & 0.10 & 0.08 & 0.03 & 0.03 & 0.02 & 0.03 & 0.03 \\
\hline$N$ of observations & 15423 & 7134 & 5126 & 1817 & 1346 & 44465 & 19148 & 15051 & 5740 & 4526 \\
\hline
\end{tabular}


Table 4: Sample means of variables by destination state

\begin{tabular}{|c|c|c|c|c|c|c|c|c|c|c|}
\hline \multirow[b]{2}{*}{ Destination } & \multicolumn{5}{|c|}{ Low-wage males } & \multicolumn{5}{|c|}{ Non low-wage males } \\
\hline & $\mathrm{R}$ & LWJ & NLWJ & $\mathrm{SE}$ & $\mathrm{UO}$ & $\mathrm{R}$ & LWJ & NLWJ & $\mathrm{SE}$ & $\mathrm{UO}$ \\
\hline \multicolumn{11}{|l|}{ Individual characteristics } \\
\hline Low education & 0.06 & 0.06 & 0.04 & 0.07 & 0.11 & 0.06 & 0.05 & 0.02 & 0.02 & 0.06 \\
\hline Vocational training or Abitur & 0.91 & 0.90 & 0.90 & 0.83 & 0.83 & 0.85 & 0.90 & 0.74 & 0.65 & 0.73 \\
\hline University & 0.03 & 0.03 & 0.06 & 0.11 & 0.06 & 0.10 & 0.05 & 0.24 & 0.33 & 0.21 \\
\hline Unskilled blue collar & 0.38 & 0.48 & 0.44 & 0.35 & 0.53 & 0.35 & 0.46 & 0.21 & 0.12 & 0.30 \\
\hline Skilled blue collar & 0.56 & 0.42 & 0.41 & 0.35 & 0.32 & 0.47 & 0.35 & 0.28 & 0.19 & 0.24 \\
\hline White collar & 0.06 & 0.11 & 0.15 & 0.30 & 0.15 & 0.18 & 0.19 & 0.51 & 0.69 & 0.45 \\
\hline Married & 0.58 & 0.56 & 0.61 & 0.56 & 0.50 & 0.66 & 0.60 & 0.66 & 0.65 & 0.58 \\
\hline Non-German & 0.14 & 0.16 & 0.15 & 0.18 & 0.22 & 0.13 & 0.13 & 0.10 & 0.11 & 0.14 \\
\hline \multicolumn{11}{|l|}{ During last 7 years } \\
\hline Years of employment & 5.66 & 5.62 & 5.72 & 5.44 & 5.33 & 6.15 & 6.20 & 6.34 & 6.24 & 6.16 \\
\hline Years of tenure at last employer & 3.93 & 2.96 & 2.64 & 3.50 & 3.18 & 4.20 & 3.53 & 3.19 & 3.70 & 3.90 \\
\hline Years of unemployment & 0.71 & 0.71 & 0.59 & 0.56 & 0.71 & 0.39 & 0.36 & 0.24 & 0.22 & 0.27 \\
\hline Number of employers & 2.36 & 3.07 & 3.19 & 2.49 & 2.76 & 2.23 & 2.70 & 2.77 & 2.43 & 2.37 \\
\hline Past recall & 0.34 & 0.14 & 0.15 & 0.15 & 0.19 & 0.34 & 0.14 & 0.10 & 0.11 & 0.17 \\
\hline Past labor market program & 0.31 & 0.38 & 0.34 & 0.32 & 0.36 & 0.17 & 0.24 & 0.21 & 0.18 & 0.20 \\
\hline \multicolumn{11}{|l|}{ Characteristics last job } \\
\hline Daily wage rate & 43.91 & 43.68 & 46.07 & 41.70 & 42.08 & 79.03 & 75.54 & 101.06 & 112.76 & 94.93 \\
\hline Manufacturing & 0.22 & 0.22 & 0.22 & 0.16 & 0.20 & 0.36 & 0.41 & 0.37 & 0.28 & 0.36 \\
\hline Agriculture, mining, energy & 0.17 & 0.04 & 0.05 & 0.03 & 0.04 & 0.13 & 0.02 & 0.02 & 0.01 & 0.02 \\
\hline Retail sector & 0.13 & 0.17 & 0.17 & 0.22 & 0.16 & 0.14 & 0.20 & 0.21 & 0.23 & 0.18 \\
\hline Hotels and restaurants & 0.09 & 0.08 & 0.06 & 0.11 & 0.11 & 0.03 & 0.02 & 0.02 & 0.02 & 0.02 \\
\hline Transport sector & 0.14 & 0.16 & 0.18 & 0.12 & 0.13 & 0.12 & 0.13 & 0.09 & 0.05 & 0.08 \\
\hline Economic and financial services & 0.09 & 0.13 & 0.13 & 0.18 & 0.14 & 0.09 & 0.10 & 0.17 & 0.27 & 0.18 \\
\hline Public services & 0.05 & 0.06 & 0.07 & 0.14 & 0.10 & 0.12 & 0.10 & 0.10 & 0.14 & 0.15 \\
\hline Temporary agency sector & 0.11 & 0.14 & 0.12 & 0.04 & 0.10 & 0.02 & 0.03 & 0.02 & 0.01 & 0.01 \\
\hline firm size up to 50 & 0.78 & 0.63 & 0.66 & 0.74 & 0.64 & 0.70 & 0.48 & 0.53 & 0.55 & 0.46 \\
\hline Firm size $51-100$ & 0.13 & 0.18 & 0.17 & 0.17 & 0.17 & 0.12 & 0.18 & 0.18 & 0.16 & 0.15 \\
\hline Firm size $101-250$ & 0.06 & 0.12 & 0.11 & 0.06 & 0.11 & 0.08 & 0.16 & 0.14 & 0.12 & 0.15 \\
\hline Firm size 251 and more & 0.03 & 0.06 & 0.06 & 0.03 & 0.08 & 0.09 & 0.18 & 0.15 & 0.17 & 0.24 \\
\hline \multicolumn{11}{|l|}{ Federal state } \\
\hline Nordrhein-Westfalen & 0.18 & 0.21 & 0.23 & 0.23 & 0.23 & 0.20 & 0.25 & 0.27 & 0.26 & 0.28 \\
\hline Schleswig-Holstein/Hamburg & 0.03 & 0.03 & 0.05 & 0.04 & 0.05 & 0.05 & 0.05 & 0.06 & 0.05 & 0.06 \\
\hline Niedersachsen/Bremen & 0.06 & 0.07 & 0.10 & 0.08 & 0.08 & 0.13 & 0.10 & 0.11 & 0.10 & 0.11 \\
\hline Hessen & 0.03 & 0.04 & 0.07 & 0.06 & 0.06 & 0.06 & 0.07 & 0.08 & 0.09 & 0.08 \\
\hline Rheinland-Pfalz/Saarland & 0.03 & 0.03 & 0.05 & 0.05 & 0.05 & 0.06 & 0.06 & 0.07 & 0.06 & 0.06 \\
\hline Baden-Württemberg & 0.04 & 0.06 & 0.10 & 0.06 & 0.08 & 0.07 & 0.11 & 0.14 & 0.13 & 0.13 \\
\hline Bayern & 0.07 & 0.08 & 0.12 & 0.11 & 0.10 & 0.21 & 0.13 & 0.15 & 0.16 & 0.15 \\
\hline Brandenburg/Berlin & 0.15 & 0.15 & 0.09 & 0.13 & 0.13 & 0.06 & 0.08 & 0.05 & 0.07 & 0.06 \\
\hline Mecklenburg-Vorpommern & 0.10 & 0.06 & 0.04 & 0.05 & 0.05 & 0.04 & 0.03 & 0.01 & 0.02 & 0.01 \\
\hline Sachsen & 0.20 & 0.16 & 0.08 & 0.14 & 0.10 & 0.06 & 0.07 & 0.03 & 0.04 & 0.03 \\
\hline Sachsen-Anhalt & 0.11 & 0.10 & 0.06 & 0.06 & 0.06 & 0.05 & 0.05 & 0.02 & 0.02 & 0.02 \\
\hline$N$ of observations & 2617 & 5090 & 1829 & 1171 & 2997 & 3849 & 5441 & 17527 & 6923 & 8075 \\
\hline
\end{tabular}

Note: R = Recall, LWJ = Low-wage job, NLWJ = Non low-wage job, SE = Self-employment, UO = Unknown or other 


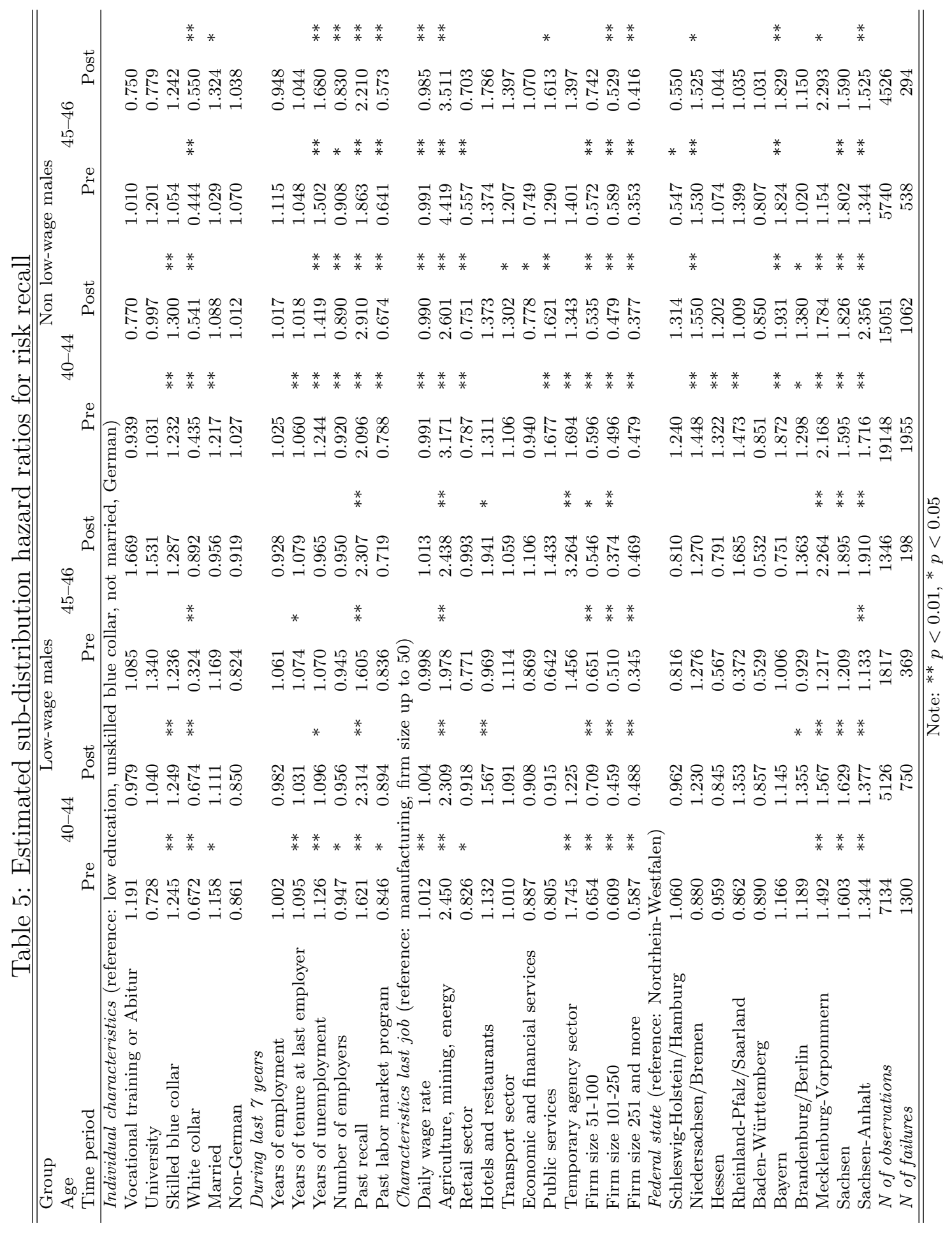




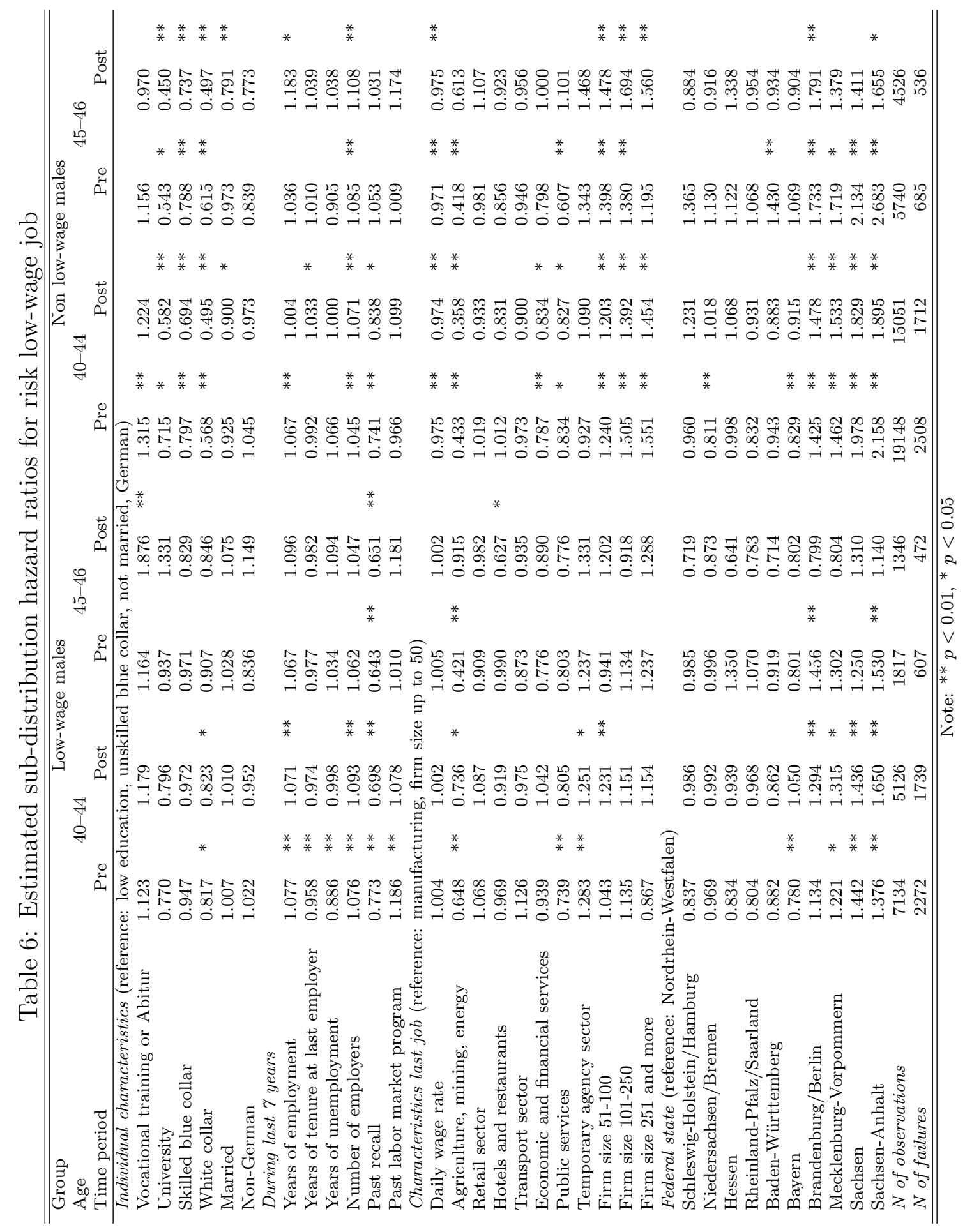




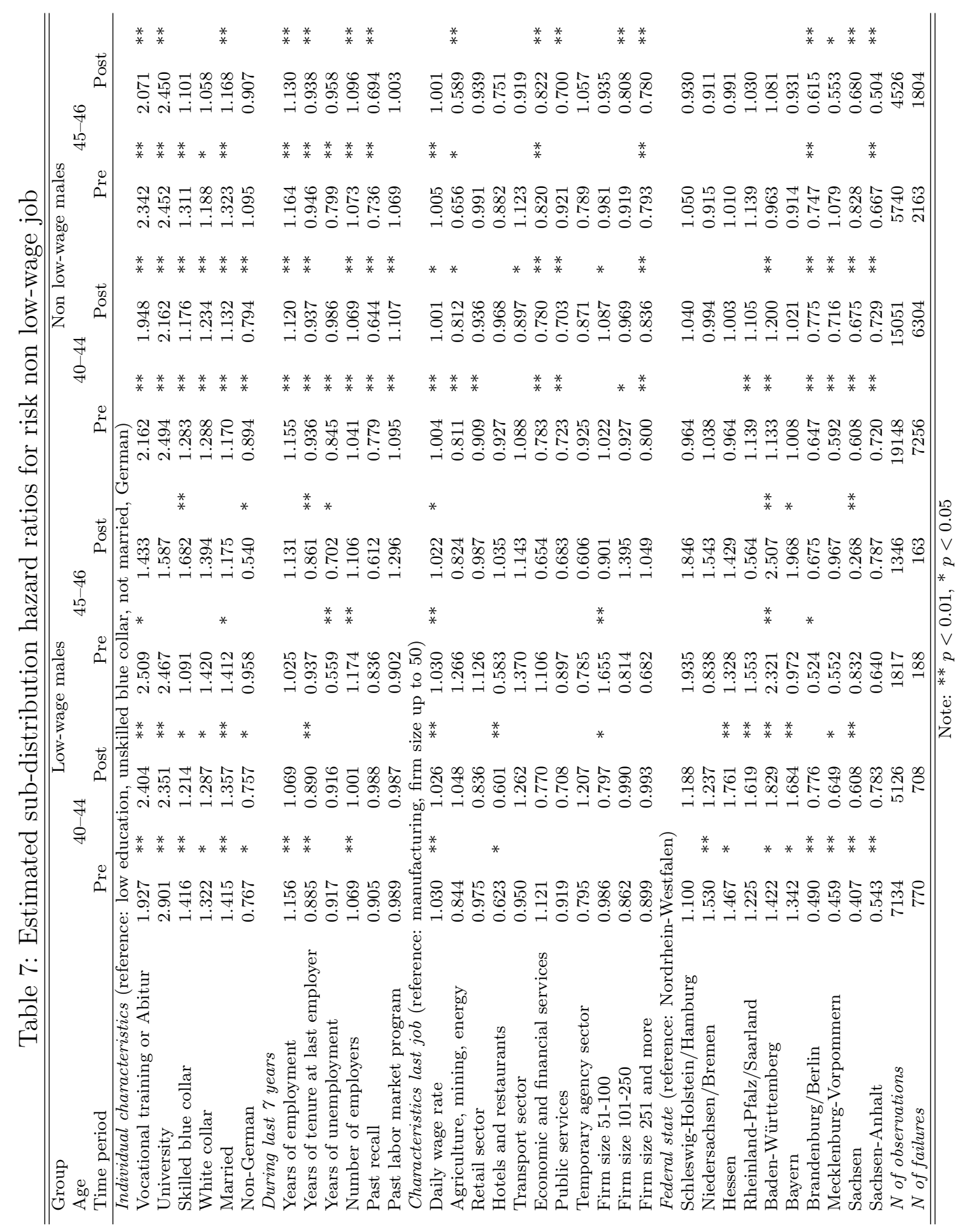




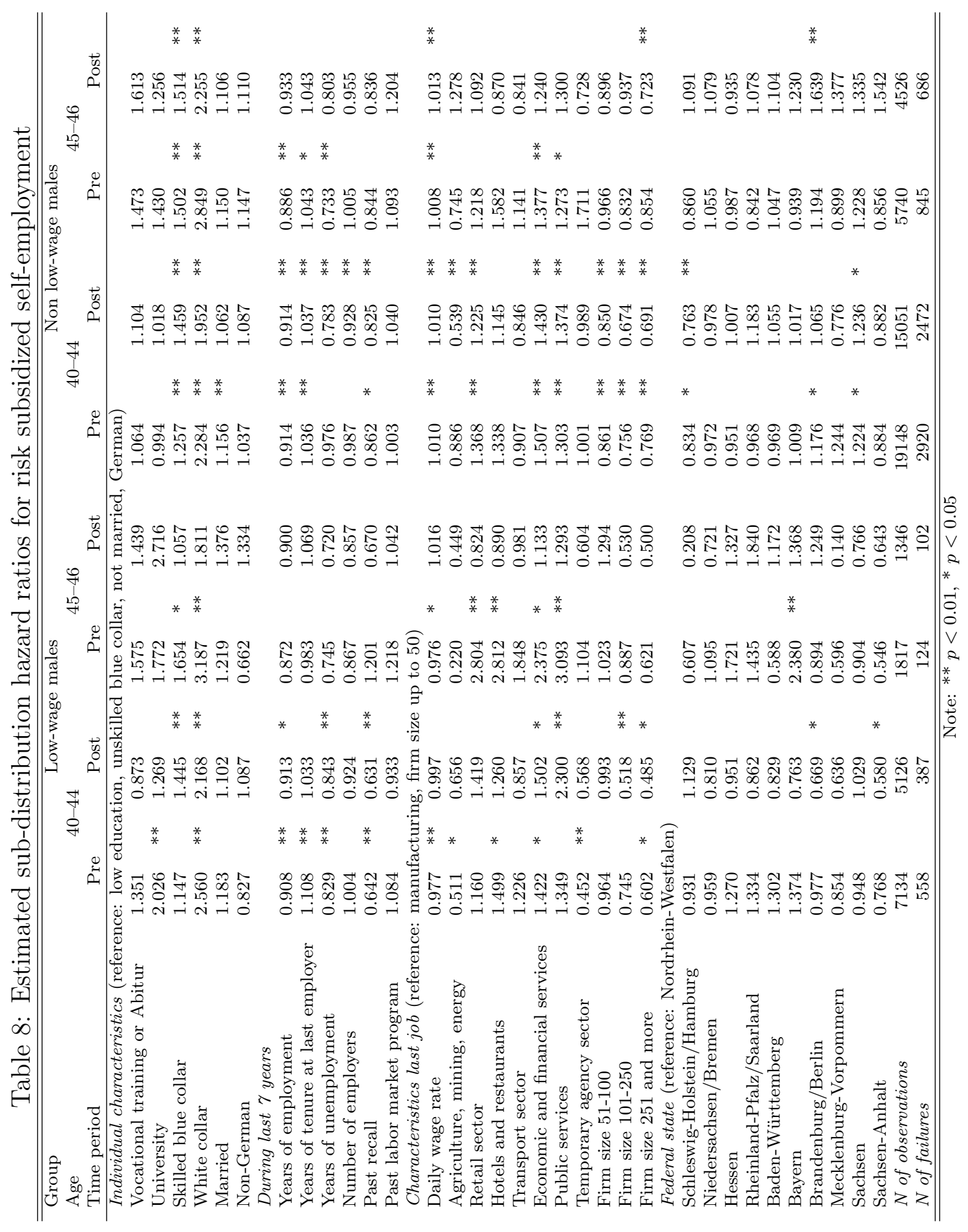




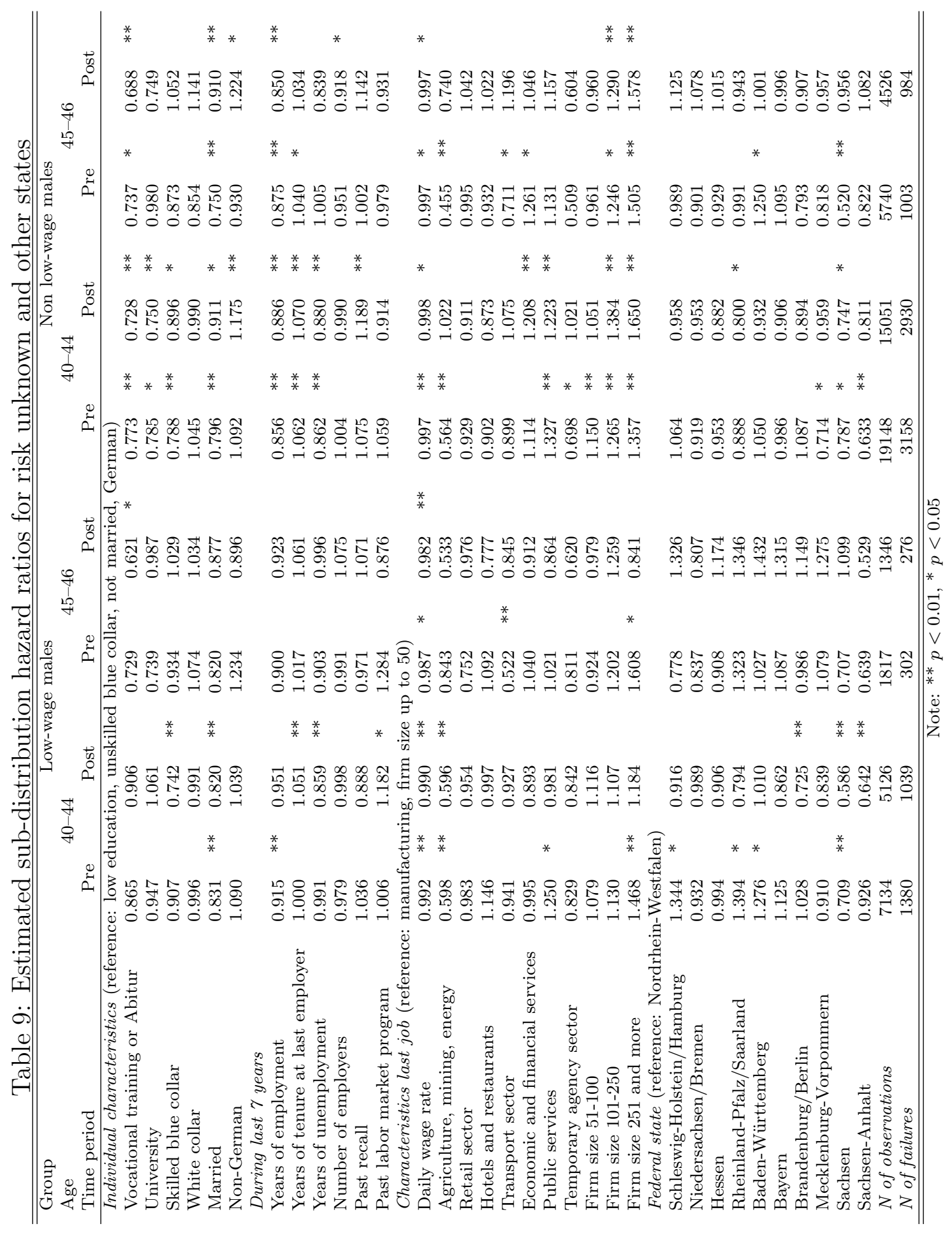


Figure 5: Estimated reform effects on $\tilde{F}_{j}$ for subsidized self-employment of non low-wage males at the mean of the regressors.

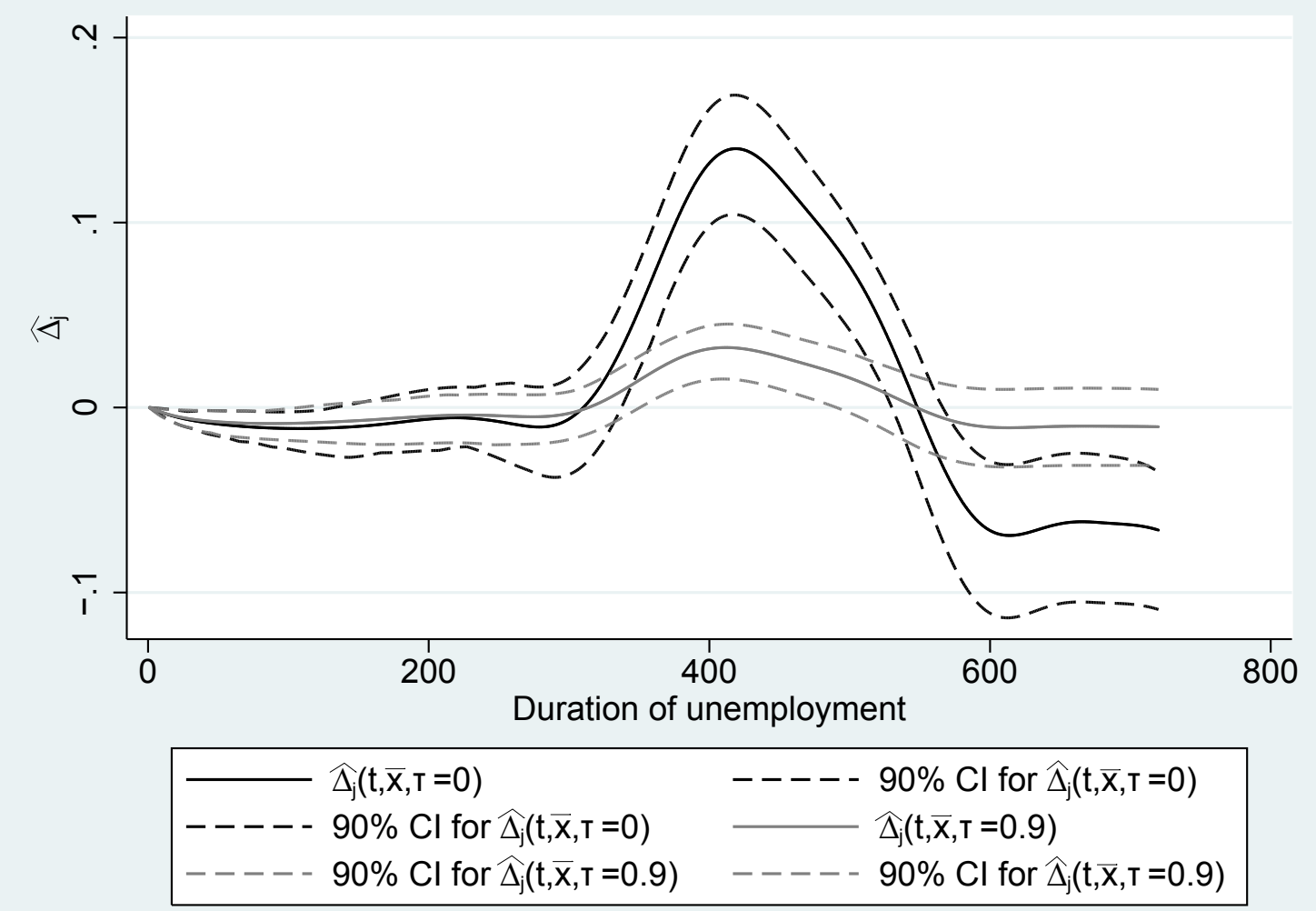




\section{References}

[1] Arntz, M., Lo, S.M.S. and Wilke, R.A. (2008) Bounds Analysis of Competing Risks: A Nonparametric Evaluation of the Effect of Unemployment Benefits on Migration in Germany, FDZ Methodenreport, 06/2008, IAB Nuremberg.

[2] BA Statistik (2010), Beschftigungsstatistik: Sozialversicherungspflichtige Arbeitsentgelte, Sonderbericht der Statistik der BA.

[3] Bond, S.J. and Shaw, J.E.H. (2006) Bounds on the covariate-time transformation for competing-risks survival analysis, Lifetime Data Analysis, 12, 285-303.

[4] Cox, D.R. (1962), Renewal Theory, London.

[5] Dlugosz, S., Stephan, G. and Wilke, R.A. (2009), Fixing the leak: Unemployment incidence before and after the 2006 reform of unemployment benefits in Germany, IAB Discussion Paper, $25 / 2009$.

[6] Fine J.P. and Gray R.J. (1999), A proportional hazards model for the subdistribution of a competing risk, Journal of the American Statistical Association, 94, 496-509.

[7] Fitzenberger, B., Osikominu, A. and Völter, R. (2006), Imputation rules to improve the education variable in the IAB employment subsample, Schmollers Jahrbuch, 126, 405-436.

[8] Hunt, J. (1995), The Effect of Unemployment Compensation on Unemployment Duration in Germany Journal of Labor Economics, 13, 88-120.

[9] Honoré, B. and Lleras-Muney, A. (2006), Bounds in Competing Risks Models and the War on Cancer, Econometrica, 74, 1675-?1698.

[10] Jeong, J.H. and Fine, J.P. (2007), Parametric regression on cumulative incidence function, Biostatistics, 8, 184-196.

[11] Lo, S.M.S. and Wilke, R.A. (2010), A copula model for dependent competing risks, Journal of the Royal Statistical Society Series C, 59, 359-376.

[12] Lo, S.M.S. and Wilke, R.A. (2011), A Regression Model for the Copula Graphic Estimator., Discussion papers in Economics, No. 11/04, University of Nottingham. 
[13] Lee, S. and R.A. Wilke (2009), Reform of Unemployment Compensation in Germany: A nonparametric Bounds Analysis using Register Data, Journal of Business and Economic Statistics, $27,176-192$.

[14] Mortensen, D.T. (1977), Unemployment Insurance and Job Search Decisions, Industrial and Labor Relations Review, 30, 505-517.

[15] Nelsen, R.B. (2006), An Introduction to Copulas, 2nd Edition, Springer, New York.

[16] Oakes,D. (1989), Bivariate survival models induced by frailties, Journal of the American Statistical Association, 84, 487-?493.

[17] Peng, L. and Fine, J.P. (2009), Competing Risks Quantile Regression, Journal of the American Statistical Association, 104, 1440-1453.

[18] Peterson, A.V. (1976), Bounds for a Joint Distribution With Fixed Sub-Distribution Functions: Application to Competing Risks, Proceedings of the National Academy of Science, 73, $11-13$.

[19] Rivest, L. and Wells, M.T. (2001) A Martingale Approach to the Copula-Graphic Estimator for the Survival Function under Dependent Censoring, Journal of Multivariate Analysis, 79, $138-155$.

[20] Schmieder J.F., von Wachter, T. and Bender, S. (2012), The Effects of Extended Unemployment Insurance over the Business Cycle: Evidence from Regression Discontinuity Estimates Over Twenty Years, Quarterly Journal of Economics, forthcoming.

[21] Tsiatis, A. (1975), A Nonidentifiability Aspect of the Problem of Competing Risks, Proceedings of the National Academy of Sciences, 72, 20-22.

[22] van den Berg, G. (1990), Nonstationarity in Job Search Theory, The Review of Economic Studies, 57, 255-277.

[23] van Ours, J.C.. and Vodopivec, M. (2006), How Shortening the Potential Duration of Unemployment Benefits Affects the Duration of Unemployment: Evidence from a Natural Experiment, Journal of Labor Economics, 24, 351-378. 
[24] Wichert, L. and Wilke, R.A. (2012), Which factors safeguard employment? An analysis with misclassified German register data. Journal of the Royal Statistical Society A, 175, 135-151.

[25] Zheng, M. and Klein, J.P. (1995), Estimates of marginal survival for dependent competing risks based on assumed copula. Biometrika, 82, 127-138. 